\title{
Article \\ Bimetallic Nanowires on Laser-Patterned PEN as Promising Biomaterials
}

\author{
Jana Pryjmaková ${ }^{1} \mathbb{D}$, Markéta Kaimlová $^{1}$, Barbora Vokatá ${ }^{2}$, Tomáš Hubáček ${ }^{3}$, Petr Slepička ${ }^{1}$, Václav Švorčík ${ }^{1}$ \\ and Jakub Siegel ${ }^{1, *(D)}$
}

1 Department of Solid State Engineering, University of Chemistry and Technology Prague, 16628 Prague, Czech Republic; pryjmakj@vscht.cz (J.P.); polivkoa@vscht.cz (M.K.); slepickp@vscht.cz (P.S.); svorcikv@vscht.cz (V.Š.)

2 Department of Microbiology, University of Chemistry and Technology Prague, 16628 Prague, Czech Republic; vokataa@vscht.cz

3 Biology Centre of the Czech Academy of Sciences, SoWa National Research Infrastructure, Na Sádkách 7, 37005 České Budejovice, Czech Republic; hubacektom@gmail.com

* Correspondence: jakub.siegel@vscht.cz; Tel.: +420-220-445-149

check for updates

Citation: Pryjmaková, J.; Kaimlová, M.; Vokatá, B.; Hubáček, T.; Slepička, P.; Švorčík, V.; Siegel, J. Bimetallic Nanowires on Laser-Patterned PEN as Promising Biomaterials. Nanomaterials 2021, 11, 2285. https:// doi.org/10.3390/nano11092285

Academic Editor: Andrew Pike

Received: 29 June 2021

Accepted: 1 September 2021

Published: 2 September 2021

Publisher's Note: MDPI stays neutral with regard to jurisdictional claims in published maps and institutional affiliations.

\begin{abstract}
As inflammation frequently occurs after the implantation of a medical device, biocompatible, antibacterial materials must be used. Polymer-metal nanocomposites are promising materials. Here we prepared enhanced polyethylene naphthalate (PEN) using surface modification techniques and investigated its suitability for biomedical applications. The PEN was modified by a KrF laser forming periodic ripple patterns with specific surface characteristics. Next, Au/Ag nanowires were deposited onto the patterned PEN using vacuum evaporation. Atomic force microscopy confirmed that the surface morphology of the modified PEN changed accordingly with the incidence angle of the laser beam. Energy-dispersive X-ray spectroscopy showed that the distribution of the selected metals was dependent on the evaporation technique. Our bimetallic nanowires appear to be promising antibacterial agents due to the presence of antibacterial noble metals. The antibacterial effect of the prepared $\mathrm{Au} / \mathrm{Ag}$ nanowires against $E$. coli and S. epidermidis was demonstrated using $24 \mathrm{~h}$ incubation with a drop plate test. Moreover, a WST-1 cytotoxicity test that was performed to determine the toxicity of the nanowires showed that the materials could be considered non-toxic. Collectively, these results suggest that prepared $\mathrm{Au} / \mathrm{Ag}$ nanostructures are effective, biocompatible surface coatings for use in medical devices.
\end{abstract}

Keywords: surface modification; nanostructure; polymer; bimetallic nanowires; biocompatibility; antibacterial properties

\section{Introduction}

Advances in manufacturing and processing technologies have resulted in polymers being used in a wide range of medical and pharmaceutical applications [1,2]. These applications include artificial blood vessels, orthopaedic implants, surgical instruments, wound dressing and drug delivery. As most of these uses involve contact with the body, the polymers must have highly-tailored surface properties. Together with surface chemistry, properties such as surface morphology, roughness and wettability have a crucial influence on the interaction between an implant and a human body. These properties also play a significant role in ensuring that a medical device functions correctly and that its introduction does not lead to inflammation [3] or bacterial infection [4,5]. In particular, bacteriosis can occur due to many reasons ranging from the simple insertion of foreign material to the inadequate sterilisation or poor storage of a medical device.

Various surface modification techniques can be used to prevent bacteriosis. These include drug impregnation [6], the addition of an antibacterial agent during polymerisation [7] or the application of anti-adhesive/antibacterial coatings [8-10]. Generally, organic 
compounds are used as antibacterial coatings. Although nanometals are gaining attention for use in antibacterial coatings with an organic base, the use of pure metal coatings remains rare.

In this context, laser surface texturing (LST) is an excellent technique for the preparation of a platform suitable for the anchoring of metallic nanostructures. Under specific conditions, LST can create a laser-induced periodic surface structure (LIPSS), or so-called ripples, on the polymer surface [11]. The most important conditions are that the laser emits ultraviolet (UV) light and that the polymer substrate absorbs in the UV range (e.g., presence of structures with aromatic compounds) [12]. Thus, ripple patterns can be created on the surfaces of various polymers such as polyether ether ketone (PEEK) [13], polystyrene (PS) [14], polyethylene terephthalate (PET) [15] and polyethylene naphthalate (PEN) [16]. The ensuing ripple structure not only provides higher surface roughness and wettability but also changes the surface chemistry in ways that are important for implant-tissue interaction.

Moreover, those structures offer the possibility of creating metallic nanowires using a vacuum evaporation technique (VET). VET is an effective physical vapour deposition technique for metallic nanomaterial synthesis. This technique offers several advantages including the control of layer thickness and a wide choice of substrates. Thus, while the applicability of a pure polymer is restricted in some ways, the use of a polymer-metal nanocomposite can extend the range of potential medical and pharmaceutical applications. Furthermore, metallic nanostructures can introduce novel physical and biological properties [1]. The use of certain metallic agents enables the preparation of biocompatible materials that can support cell proliferation [17-19] and antibacterial activity $[9,20,21]$. Metals such as copper [22], silver [23] and gold [24] are well known for their efficient antibacterial activity. However, metallic nanostructures can also be toxic in nanoparticle $[25,26]$ or nanowire [27] form. When they exert an unfavourable influence on tissue, they can inhibit the proliferation of healthy cells and even kill them.

In this work, we focus on the surface modification of PEN in such a way that the resulting material is both biocompatible and antibacterial. To achieve this, we combined silver as the antibacterial agent and gold as the biocompatible material. A $248 \mathrm{~nm} \mathrm{KrF}$ excimer laser and vacuum evaporation were used to prepare the $\mathrm{Au} / \mathrm{Ag}$ nanowires. Using a combination of cytotoxicity and drop plate tests, we show that our material is biocompatible and demonstrates antibacterial effects against both Gram-positive $\left(\mathrm{G}^{+}\right)$and Gram-negative $\left(\mathrm{G}^{-}\right)$bacteria.

\section{Materials and Methods}

\subsection{Materials and Apparatus}

In this study, a foil of polyethylene naphthalate (PEN, thickness of $50 \mu \mathrm{m}$, supplied by Goodfellow, Ltd., Huntington, UK) was used as a substrate. The samples, having $1 \times 1 \mathrm{~cm}^{2}$ areas, were cleansed of impurities using a stream of nitrogen and then modified using the linearly polarised light of a KrF laser (COMPexPro 50 F, Coherent, Inc., Santa Clara, CA, USA). Polarised light with a $248 \mathrm{~nm}$ wavelength was created using a UV-grade fused silica prism (model PBSO 248-100). The ripples were irradiated under the following conditions: 6000 pulses, pulse duration $20-40 \mathrm{~ns}$, frequency $10 \mathrm{~Hz}$ and an aperture with an area of $5 \times 10 \mathrm{~mm}^{2}$. The incidence angle of the laser beam was set to $0^{\circ}, 22.5^{\circ}$ and $45^{\circ}$, and laser fluency was changed to $4.5,5.9$ and $7 \mathrm{~mJ} \cdot \mathrm{cm}^{-2}$ with respect to the increased angles as well as the resulting changes in the irradiated areas.

After the modification, the $\mathrm{Au} / \mathrm{Ag}$ nanowires (Au/AgNWs) were deposited onto the patterned PEN using vacuum evaporation apparatus LEYBOLD-Heraeus (Univex 450, Cologne, Germany). Evaporation was performed at room temperature at a pressure of $3 \times 10^{-4} \mathrm{~Pa}$, a deposition rate of $0.33 \mathrm{~nm} \cdot \mathrm{s}^{-1}$ and a glancing angle of $\varphi=70^{\circ}$ with respect to the sample surface, using resistively heated tungsten crucible. The deposition was carried out in two steps: Firstly, the gold was deposited onto one side of the ripples, the samples were rotated $180^{\circ}$ and then the silver was deposited on the other side of the ripples. Both metals were supplied by Safina, a.s., Vestec, Czech Republic in the form of pellets 
$\left(3.18 \times 3.18 \mathrm{~mm}^{2}\right.$, purity $\left.99.99 \%\right)$. The thickness of the deposited metals (20 nm of gold corresponded to $\Delta \mathrm{f}=490 \mathrm{~Hz} ; 20 \mathrm{~nm}$ of Ag corresponded to $\Delta \mathrm{f}=640 \mathrm{~Hz}$ ) was monitored in situ by the oscillation of the quartz crystal. For thickness analysis, the scratch method was used [28]. A silica glass substrate was deposited simultaneously with the polymer samples. Next, scratches were created on the glass surface in five different positions and measured by atomic force microscopy (AFM VEECO CP II, Veeco Instruments, Inc., New York, NY, USA). Thickness variations did not exceed $5 \%$.

\subsection{Analytical Methods}

The surface morphology of PEN, modified PEN (PEN 0/22.5/45 ) and modified PEN with $\mathrm{Au} / \mathrm{AgNWs}\left(\mathrm{Au} / \mathrm{Ag}\right.$ PEN $0 / 22.5 / 45^{\circ}$ ) was analysed by atomic force microscopy (AFM VEECO CP II, Veeco Instruments, Inc., New York, NY, USA). The AFM images were taken using a Digital Instruments CP II setup. Samples were tacked to the sample holder using double-sided adhesive tape. An oxide-sharpened, P-doped RTESPA-CP silica probe (spring constant of $0.9 \mathrm{~N} \cdot \mathrm{m}^{-1}$, Veeco Instruments, Inc., New York, NY, USA) was used at an approximate resonant frequency of $300 \mathrm{~Hz}$. The probe was attached to a flexible micro-cantilever. The 'taping mode' was chosen for measurement to minimise the damage of the sample surfaces. To obtain the representative data, four areas were scanned with a line scanning rate of $0.5 \mathrm{~Hz}$. The same AFM method was used to measure parameters including surface roughness $\left(R_{a}\right)$, periodicity $(\Lambda)$ and height $(h)$. The surface roughness $R_{a}$, characterised by the mean roughness value, represents an arithmetic average of the deviation from the centre plane of the sample. The periodicity (a repetition of ripples/nanowires) was measured as the distance between the two nearest bases/tops of these nanostructures. The heights of ripples/nanowires were measured from the bases to the tops. The parameters as $R_{\mathrm{a}}, \Lambda$ and $h$ were evaluated in ten different positions, then arithmetical means and standard deviations were calculated. Characteristic values of roughness (average roughness $R_{\mathrm{a}}$ ), as well as periodicity and height, were obtained from AFM scans in a software NanoScope Analysis v1.8. Variations of these parameters did not exceed $5 \%$.

Samples with deposited $\mathrm{Au} / \mathrm{AgNWs}$ were also visualised using scanning electron microscopy (SEM). The metal-polymer interface was detected by a focused ion beam (FIB), model SEM LYRA3 GMU (FIB-SEM, Tescan, Brno, Czech Republic). FIB cuts were made by a Ga ion beam. Investigated samples were polished using a lower beam current to provide a clean and flat surface. Images were taken at an angle of $54.8^{\circ}$ with a voltage of $5 \mathrm{kV}$.

The concentrations of gold $(\mathrm{Au})(3 \mathrm{~d})$, silver $(\mathrm{Ag})(3 \mathrm{~d})$, carbon $(\mathrm{C})(1 \mathrm{~s})$ and oxygen (O) (1s) on pristine, modified and metal-coated sample surfaces were determined using angle-resolved X-ray photoelectron spectroscopy (AR-XPS). For these measurements, an ESCAProbeP spectrometer (Omicron Nanotechnology GmbH, Taunusstein, Germany) was used. A monochrome X-ray beam with an energy of $1486.7 \mathrm{eV}$ was used as a source. The photoelectron spectra were measured stepwise with a step of $0.05 \mathrm{eV}$. The samples were analysed at angles of $90^{\circ}$ (perpendicular to the sample) and $14^{\circ}$ from the left $(+)$ and right $(-)$ sides with respect to the sample surface. The spectra were evaluated by CasaXPS software. The concentration of elements was given in $\%$.

Energy-dispersed X-ray spectroscopy with a $2 \mathrm{~mm}$ 2SDD (SEM-EDS, X-MaxN, Oxford Instruments, Abingdon-on-Thames, UK) detector was used to clarify the Au-Ag interface. Before measurement, samples were coated with a gold layer with a thickness of $20 \mathrm{~nm}$ and secured with conductive carbon tape to discharge them. For the analyses of elements, an electron beam with a voltage of $10 \mathrm{kV}$ was used. Data were evaluated using AZtecEnergy software v3.1.

As the PEN was coated with metals possessing optical activity, absorption in the range of 350-900 nm was studied using the UV-Vis spectrometer model Lambda 25 (Perkin-Elmer, Inc., Waltham, MA, USA). Due to the presence of periodic arrays, absorption spectra were measured using polarised light with a perpendicular orientation to the nanowires. To obtain the polarised light, a WP25L-UB polariser $(250-4000 \mathrm{~nm})$ supplied by Thorlabs was 
added in front of a beam output. The scanning rate was set at $240 \mathrm{~nm} \cdot \mathrm{min}^{-1}$. Data were evaluated using Perkin-Elmer UV WinLab software v4.2.

To observe changes in wettability, contact angles were measured using goniometer model KRÜSS DSA 100 (KRÜSS, Hamburg, Germany) using a sessile drop method. An automatic pipette applied 10 drops of $2 \mu \mathrm{L}$ of distilled water to the surface of the PEN (used in a pristine form), the PEN $0 / 22.5 / 45^{\circ}$ and the $\mathrm{Au} / \mathrm{Ag}$ PEN $0 / 22.5 / 45^{\circ}$. Subsequently, the contact angle was calculated using KRÜSS Advance software v2.0 using a three-point method. An arithmetical mean and standard deviation were determined from obtained values.

Inductively coupled plasma mass spectroscopy (ICP-MS) was used to study the impacts of $\mathrm{Ag}^{+}$and $\mathrm{Au}^{\mathrm{n}+}$ ions on the antibacterial effect of the final material. To determine the concentrations of the released ions, leachates were created under the same conditions as in the antibacterial tests (see below). Unmodified PEN and modified PEN with Au/AgNWs were immersed into $5 \mathrm{~mL}$ of physiological solution (PS, $0.9 \% \mathrm{NaCl}$ ) at $24{ }^{\circ} \mathrm{C}$ for 3 and $24 \mathrm{~h}$. Control leachates were prepared in the same way. All liquid samples were prepared in triplicate. Before analysis, each leachate was centrifuged using an Optima MAX-XP ultracentrifuge (Beckman Coulter, Brea, CA, USA) at an overload of 200,000 $\mathrm{g}$ for $30 \mathrm{~min}$ to eliminate the eventual residua of solid metals. The concentrations of $\mathrm{Ag}^{+}$and $\mathrm{Au}^{\mathrm{n}+}$ ions were measured using an Agilent 8800 triple-quadrupole spectrometer (Agilent Technologies, Santa Clara, CA, USA) with an auto-sampler. A MicroMist device with a peristaltic pump was used to homogeneously inject the sample into the atomiser.

\subsection{Antibacterial Tests}

The study of the antibacterial activity of the prepared samples was performed using a drop plate method of counting viable bacteria [29]. Antibacterial activity was observed against two bacterial strains: Gram-negative $\left(\mathrm{G}^{-}\right)$Escherichia coli (DBM 3138) and Grampositive $\left(\mathrm{G}^{+}\right)$Staphylococcus epidermidis (DBM 3179). Bacteria were cultivated at $37^{\circ} \mathrm{C}$ in an orbital shaker overnight. Prepared inocula were serially diluted in sterile physiological solution (PS), and optical density was measured at $600 \mathrm{~nm}\left(\mathrm{OD}_{600}\right)$. Next, samples were immersed into $1 \mathrm{~mL}$ of PS and inoculated with $1.1 \times 10^{4}$ colony-forming units (CFUs) per $1 \mathrm{~mL}$ of E. coli and $2.2 \times 10^{4} \mathrm{CFUs}$ per $1 \mathrm{~mL}$ of S. epidermidis. Simultaneously, control samples of E. coli and S. epidermidis in PS without polymer samples were prepared. All samples were prepared in triplicate and incubated under static conditions $\left(24{ }^{\circ} \mathrm{C}\right.$, test tubes standing on the laboratory table) for 3 and $24 \mathrm{~h}$. Next, aliquots of $25 \mu \mathrm{L}$ from each sample were intensively mixed by Vortex, and 5 drops were instilled onto thirds of the pre-dried agar plates. Agar LB (Luria-Bertani) for E. coli and Agar PCA (plate count broth) for S. epidermidis were used as cultivate media. After overnight cultivation on agar plates, the numbers of CFUs of both bacteria strains were counted, and mean values with standard deviation were calculated. The whole experiment was carried out under sterile conditions.

\subsection{Cytotoxicity}

The toxicity of PEN $0 / 22.5 / 45^{\circ}$ with $\mathrm{Au} / \mathrm{AgNW}$ s was tested on human primary lung fibroblasts. Human primary lung fibroblasts (MRC-5) were obtained from the American Tissue Culture Collection (ATCC, Manassas, VA, USA) and cultured in Minimal Essential Medium supplemented with $2 \mathrm{mM}$ L-Glutamine (a stable dipeptide, Sigma-Aldrich, St. Louis, MO, USA) and 10\% foetal bovine serum (FBS, Thermo Fisher Scientific, Waltham, MA, USA). The cells were maintained at the exponential phase of growth under specific conditions $\left(37^{\circ} \mathrm{C}, 5 \% \mathrm{CO}_{2}\right.$ and $95 \%$ humidity).

For the cell viability study, PEN $0 / 22.5 / 45^{\circ}$ and $\mathrm{Au} / \mathrm{Ag}$ PEN $0 / 22.5 / 45^{\circ}$ were chosen The viability of MRC-5 cells was determined using the WST-1 test [30], which is based on the transformation of tetrazolium salt (WST-1 reagent) into coloured formazan. Cell culture plates (6-well, VWR, Radnor, PA, USA) with inserted samples were sterilised with $70 \%$ ethanol of $99.9 \%$ purity for $30 \mathrm{~min}$. Subsequently, samples were rinsed with sterile phosphate buffer (PBS, pH 7.4) and inoculated with 30,000 cells per $\mathrm{cm}^{2}$ in $2.5 \mathrm{~mL}$ of the 
complete cultivating medium in triplicate. Samples were cultivated for 24,48 and $72 \mathrm{~h}$. Next, the medium was removed, cells were rinsed with PBS, and WST-1 reagent diluted with complete phenol red-free DMEM was added. After cells were incubated for $2 \mathrm{~h}$, the medium for cell cultivation was transferred onto 96 -well plates $(100 \mu \mathrm{L}$ per well, 4 wells per sample), and absorbance was measured. Measurement was accomplished at $450 \mathrm{~nm}$ and the reference value was measured at $650 \mathrm{~nm}$. Cells cultivated on standard tissue culture polystyrene (TCPS) were used as a control.

\section{Results and Discussion}

\subsection{Surface Characterisation}

Surface morphology was studied on pristine PEN (PEN), PEN modified under different incidence angles of laser light (PEN 0/22.5/45 ) and modified PEN coated with

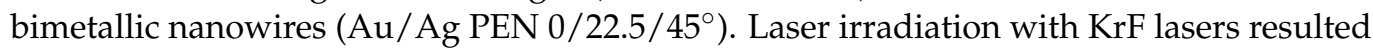
in the development of periodical arrays on the PEN, with structural parameters differing at specific light incidence angles of $0^{\circ}, 22.5^{\circ}$ and $45^{\circ}$ (see Figure 1 ). The incidence angle of the laser beam had a crucial influence on the surface roughness, periodicity and height of the final nanostructures, which are summarised in Table 1. It is obvious that increasing the incidence angle promoted surface roughness. This phenomenon has been also observed in the studies of Slepička et al. [31,32], where different values of roughness were obtained by changing laser fluency, and angle-dependent nanopatterning was created. The values for structure periodicity and height showed the same trend, which is in agreement with Equation (1) [33]:

$$
\Lambda=\frac{\lambda}{n-\sin \theta}
$$

where $\lambda$ represents the wavelength of the laser light used, $n$ is the effective refractive index of the environment and $\theta$ is the incidence angle of the laser beam. The nanopatterning occurs due to the interference of the polarised incident beam and the scattered wave beam, which cause inhomogeneous intensity distribution on the surface and leads to a stable thermal process in the form of LIPSS. Generally, the interaction of the laser beam with the polymer surface is a complex mechanism involving a number of processes [34].

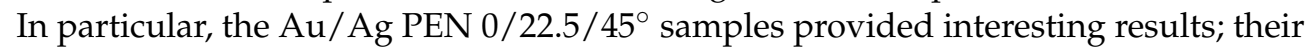
roughness was slightly lower compared to modified PEN without bimetallic nanowires. This is due to a well-described phenomenon known as the shadow effect [35]. The evaporated material, at an angle of $70^{\circ}$ with regard to the crucibles, condensed preferentially on one side of the periodical arrays and thus filled in free space between ripples. Therefore, in the case of bimetallic nanowires where gold and silver were deposited on both sides, the difference in surface roughness was less pronounced compared to monometallic AgNWs [16].

To obtain more detailed information on the sample morphology, SE micrographs and FIB cuts were made on the surfaces of modified and metal-coated samples. Results from SEM confirmed the presence of periodically arranged nanostructures (Figure 2). The trend of increased periodicity once the incident angle was higher is obvious, which is in correlation with the periodicity derived from AFM. However, the localisation of metals on the PEN surface was not clear from the SE micrographs. Therefore, FIB-SEM analysis was performed to reveal the metal-polymer interface (see Figure 3). Due to two-step deposition, the homogeneous distribution of metals was clearly noticeable. Nevertheless, FIB-SEM analysis did not provide information about the respective distribution of gold and silver. For this reason, AR-XPS and EDS spectroscopies were carried out to determine the surface elemental composition. 

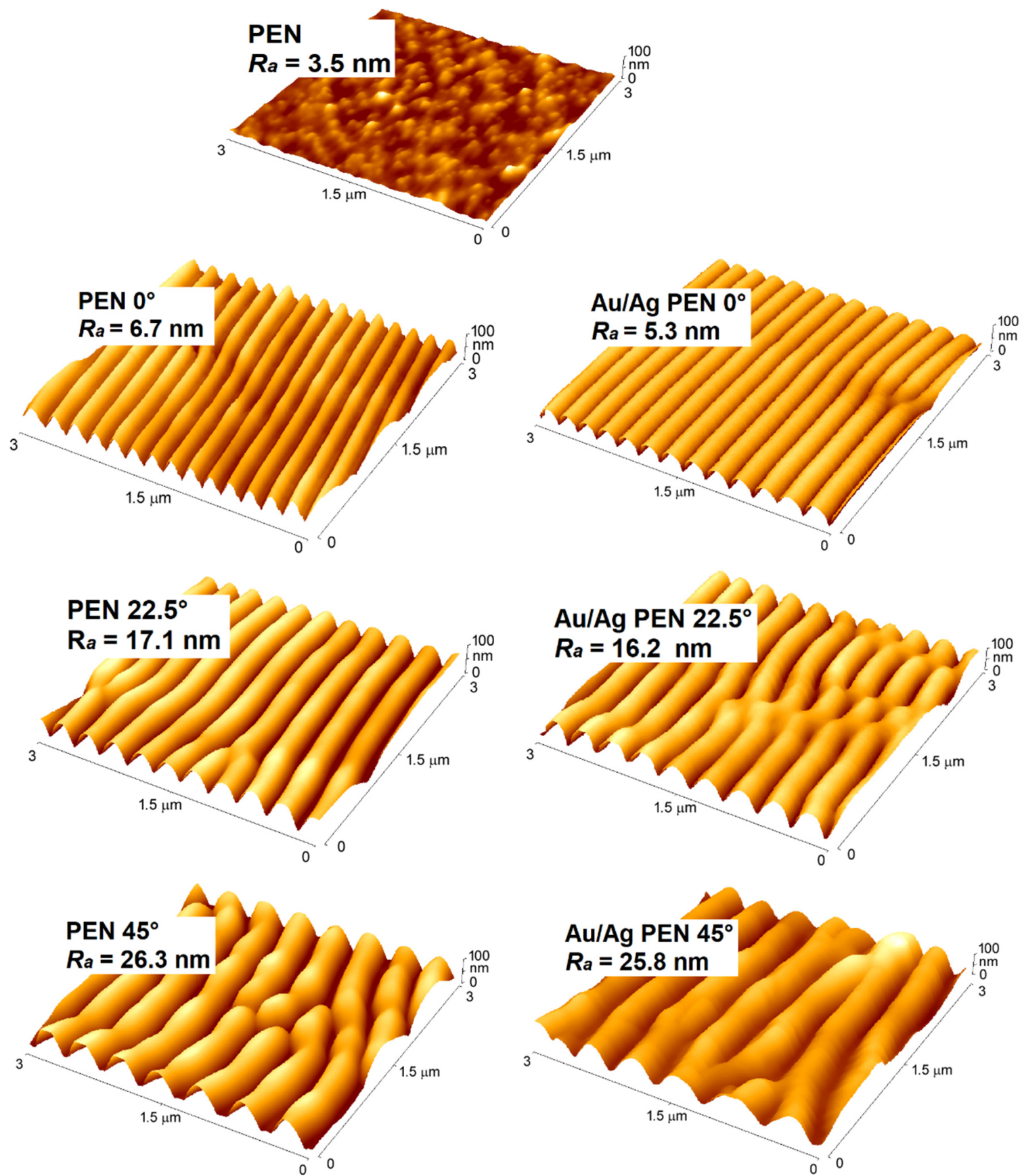

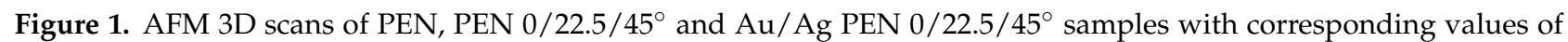
surface roughness $\left(R_{a}\right)$.

Table 1. Measured values of surface roughness $\left(R_{a}\right)$, periodicity $(\Lambda)$ and height $(h)$ of PEN $\left(0 / 22.5 / 45^{\circ}\right)$ and $\mathrm{Au} / \mathrm{Ag} \mathrm{PEN}\left(0 / 22.5 / 45^{\circ}\right)$ nanopatterned surfaces.

\begin{tabular}{cccc}
\hline Sample & Ra $(\mathbf{n m})$ & $\boldsymbol{\Lambda}(\mathbf{n m})$ & $\boldsymbol{h}(\mathbf{n m})$ \\
\hline PEN & 3.5 & - & - \\
PEN 0 & 6.7 & 212.4 & 24.8 \\
PEN 22.5 & 17.1 & 307.0 & 60.5 \\
PEN 45 & 26.3 & 398.0 & 94.8 \\
Au Ag PEN 0 & 5.3 & 209.6 & 24.5 \\
$\mathrm{Au} /$ Ag PEN 22.5 & 16.2 & 303.4 & 59.4 \\
$\mathrm{Au} / \mathrm{Ag}$ PEN $45^{\circ}$ & 25.8 & 393.2 & 92.6 \\
\hline
\end{tabular}



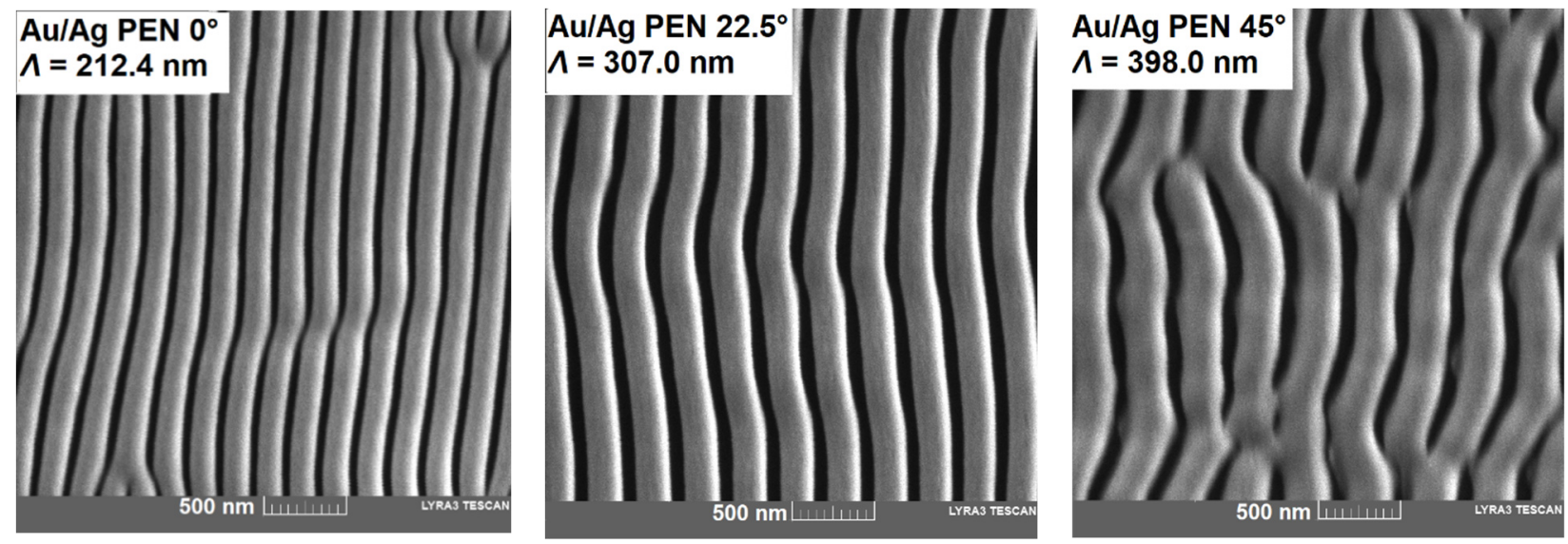

Figure 2. Micrographs from SE microscopy of Au/Ag PEN $\left(0 / 22.5 / 45^{\circ}\right)$ samples with corresponding values of periodicity $(\Lambda)$.
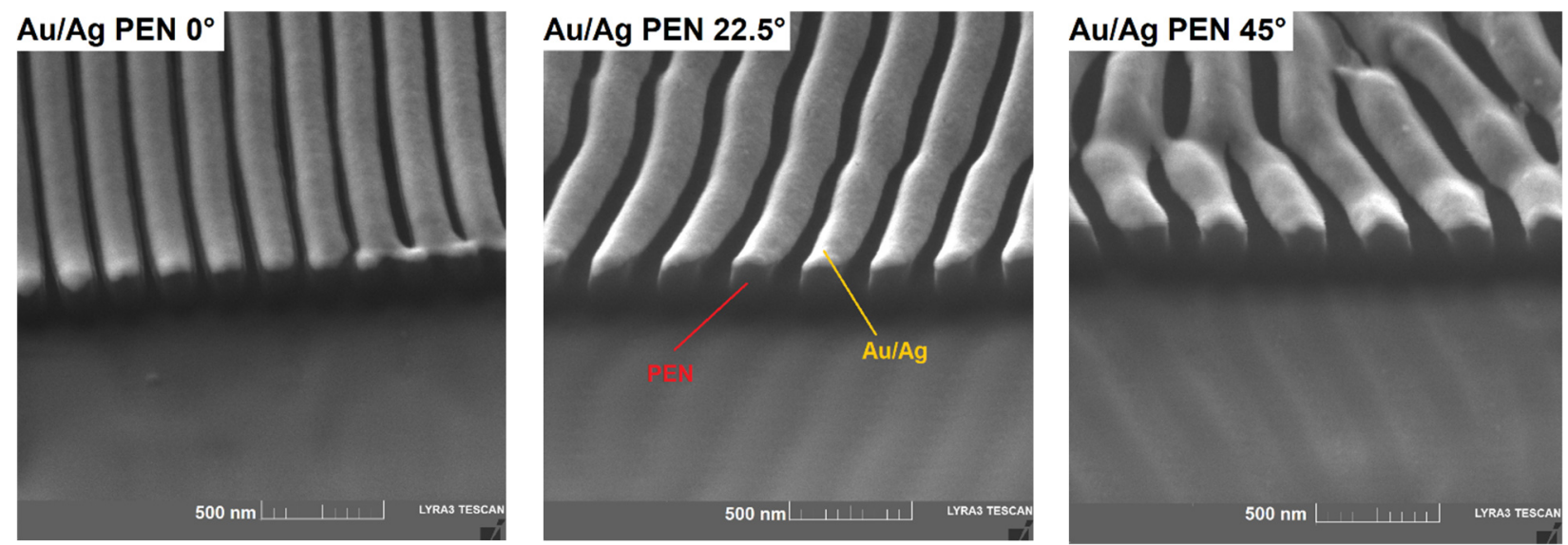

Figure 3. Micrographs from FIB-SEM showing metal-polymer interfaces on the surfaces of Au/Ag PEN $\left(0 / 22.5 / 45^{\circ}\right)$ samples.

Results from the AR-XPS analysis at angles of $90^{\circ}$ and $\pm 14^{\circ}$ (with respect to the sample surface) are summarised in Figure 4 . While at $90^{\circ}$, analytical information could be determined from about $8-10 \mathrm{~nm}$, detection at $14^{\circ}$ provided information regarding chemical composition from a very small surface area (1-2 nm) [36]. AR-XPS showed inhomogeneous distribution of metals, which is consistent with the presence of bimetallic nanowires. Slightly higher silver concentrations on the surface of the Au/Ag PEN were due to the fact that gold was deposited on the modified PEN first, followed by silver in the second step. Thus, gold was covered by silver on the ripple tops, which led to higher concentrations of silver, especially at the angle of $-14^{\circ}$. 


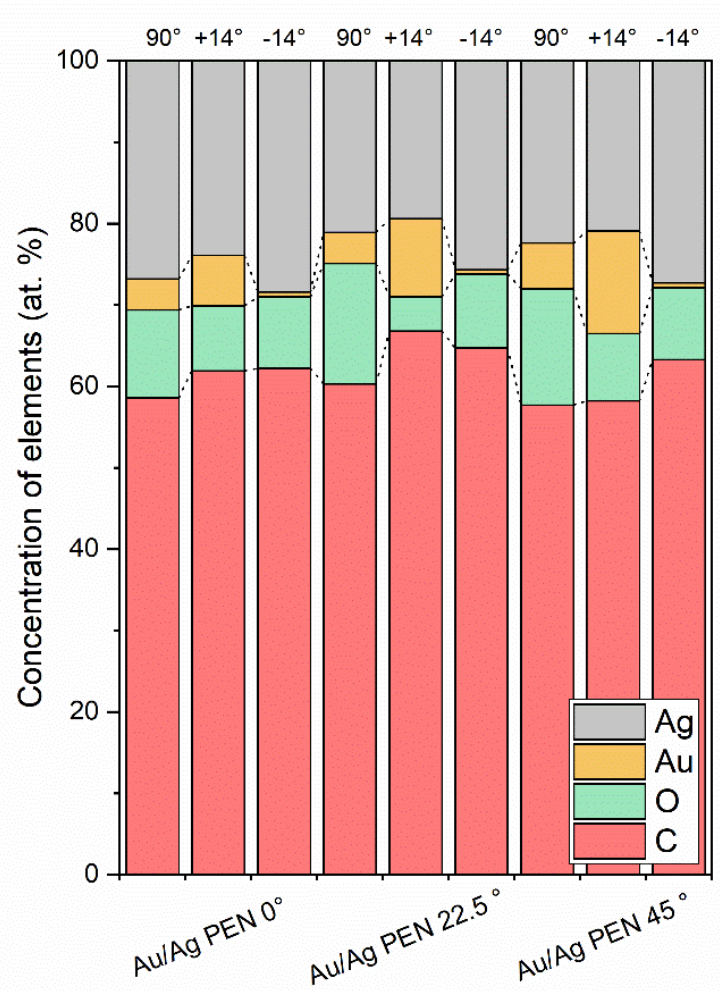

Figure 4. The concentrations of $\mathrm{Au}, \mathrm{Ag}, \mathrm{C}$ and $\mathrm{O}$ on $\mathrm{Au} / \mathrm{Ag} \mathrm{PEN} 0 / 22.5 / 45^{\circ}$ samples determined by AR-XPS.

For further understanding of the metal nanowire distribution, samples were observed using EDS spectroscopy. The distribution of individual metals is visible in the concentration profile shown in Figure 5. One can see that due to the two-step process, gold was deposited directly onto the modified polymers, while silver slightly covered Au nanowires, especially on the tops of the periodic structures. For this reason, the ripple tops showed higher concentrations of silver. Nonetheless, detected concentrations of gold and silver were similar within individual samples, pointing to the homogeneous distribution of metals in bimetallic nanowires.

$\mathrm{Au} / \mathrm{Ag} \mathrm{PEN} 0^{\circ}$
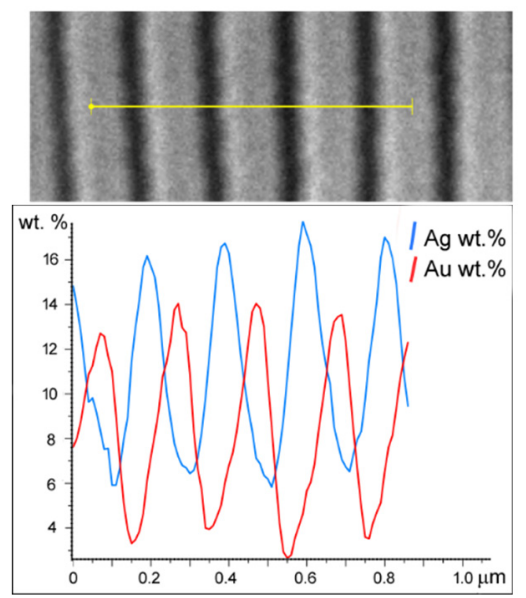

Au/Ag PEN 22.5
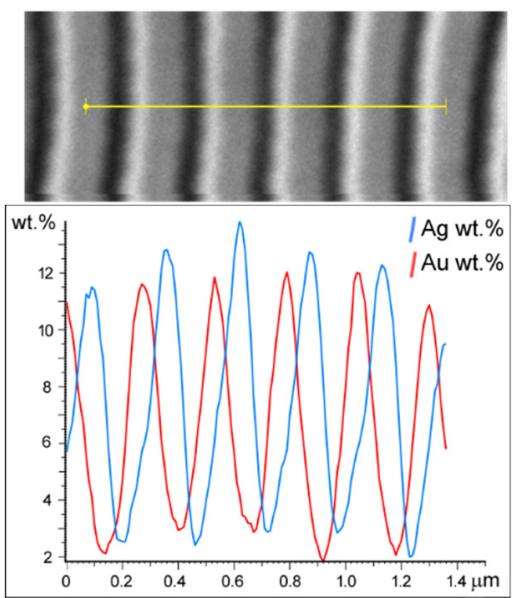

$\mathrm{Au} / \mathrm{Ag}$ PEN $45^{\circ}$

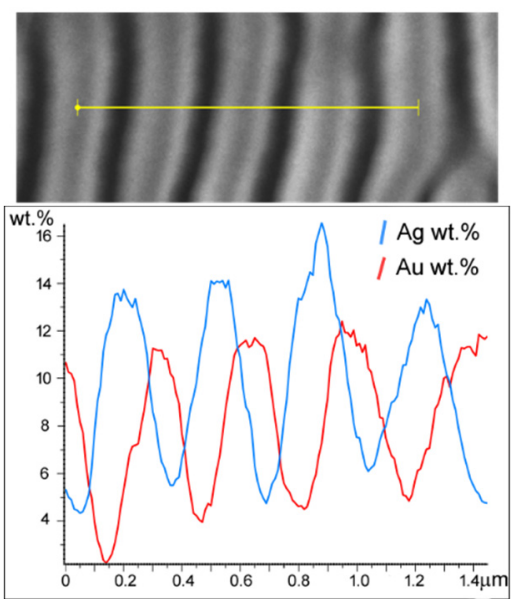

Figure 5. The concentration profiles of Ag and Au obtained by EDS spectroscopy in addition to SE micrographs of Au/Ag PEN 0/22.5/45 samples of corresponding areas. 
As polymer samples were deposited by optically active metals, their absorbance was characterised using UV-Vis spectroscopy (see Figure 6). Nanostructured metals are known for surface plasmon resonance (SPR), which is affected by the oscillation of conduction band electrons [37]. This phenomenon is accompanied by the development of the SPR absorption band in UV-Vis spectra. Most metals have their SPR maxima in the range of 10-400 nm (e.g., silver); however, the SPR peaks of some metals (e.g., copper, gold) are found in the range of 400-800. In the case of composited materials and alloys, the SPR peaks are combined, which leads to the phenomenon known as coupling. Some similarity with our results (Figure 6) can be found in the study of Gunwidjaja et al. [38], where the authors observed the plasmon coupling of silver and gold peaks on AgNWs samples coated with an AuNPs/polyallylamine composite. Compared to $\mathrm{Au} / \mathrm{Ag} \mathrm{PEN} 0^{\circ}$ and $\mathrm{Au} / \mathrm{Ag}$ PEN 22.5 $5^{\circ}$ the red-shift was evident on Au/Ag PEN $45^{\circ}$ (Figure 6c) where the maximum SPR band was in the range of $650-700 \mathrm{~nm}$. Except for plasmon coupling, pronounced interference at higher energies (350-500 nm) was observed in the case of all three samples $\left(\mathrm{Au} / \mathrm{Ag}\right.$ PEN $\left.0 / 22.5 / 45^{\circ}\right)$. This interference can be used to determine the layer thickness using the procedures given in [39].

(a)

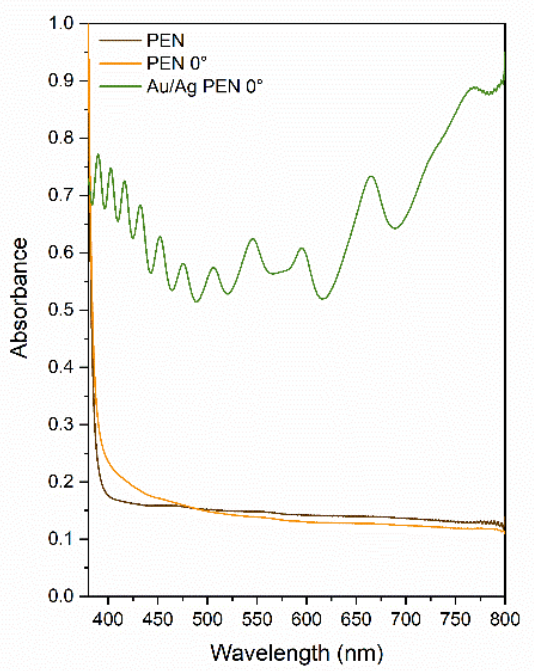

(b)

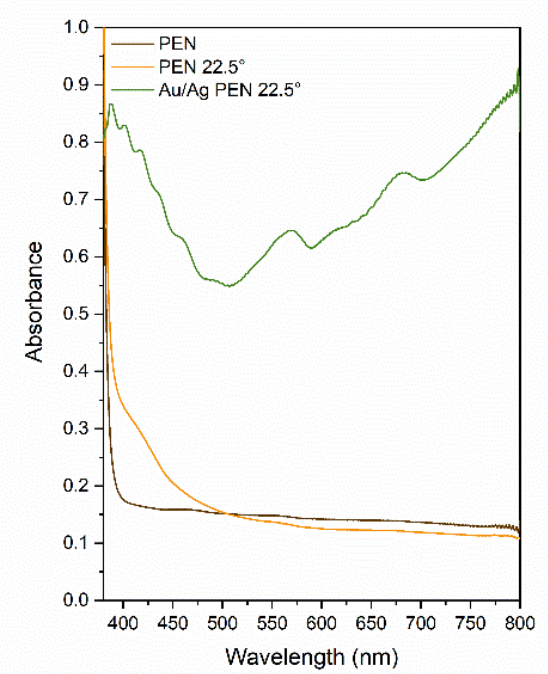

(c)

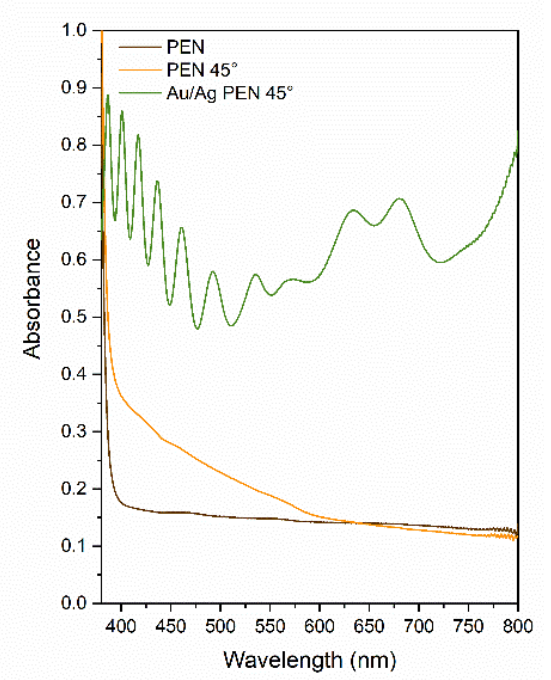

Figure 6. UV-Vis spectra of PEN, modified PEN and PEN with Au/AgNWs at incidence angles of (a) $0^{\circ},(\mathbf{b}) 22.5^{\circ}$ and (c) $45^{\circ}$.

The measurement of the contact angle (CA), important in the interaction of the potential medical device with the tissue, was carried out on the surfaces of the PEN, the $\mathrm{PEN} 0 / 22.5 / 45^{\circ}$ and the $\mathrm{Au} / \mathrm{Ag} \mathrm{PEN} 0 / 22.5 / 45^{\circ}$. It is obvious from Figure 7 that the polymer with a bimetallic nanostructure exhibited a hydrophobic character. The results show an increasing contact angle with the increasing incidence angle of the laser beam during polymer irradiation. Surprisingly, the CA of laser-modified PEN $\left(22.5^{\circ}\right.$ and $\left.45^{\circ}\right)$ was similar to that of pristine PEN $(74.1 \pm 0.3)^{\circ}$. The CA of the deposited samples was similar for each incidence angle, indicating that wettability could be influenced by the presence of metals. However, it cannot be excluded that nanostructured surface morphology may not play a role in the wettability of prepared samples. Because of periodical arrays, the water droplets could not be in contact with the sample surfaces absolutely as in the case of the Wenzel state. When air is trapped in gaps between nanostructured forms, the phenomenon is known as the Cassie-Baxter wetting state [40]. For this reason, a high CA was obtained, and the material appeared to be hydrophobic. The transition from the Cassie-Baxter state (meta-stable) to the Wenzel state (stable) is influenced by thermodynamic variables (tem- 
perature, pressure) and also by the parameters of the structures present on the sample surface (height and periodicity).

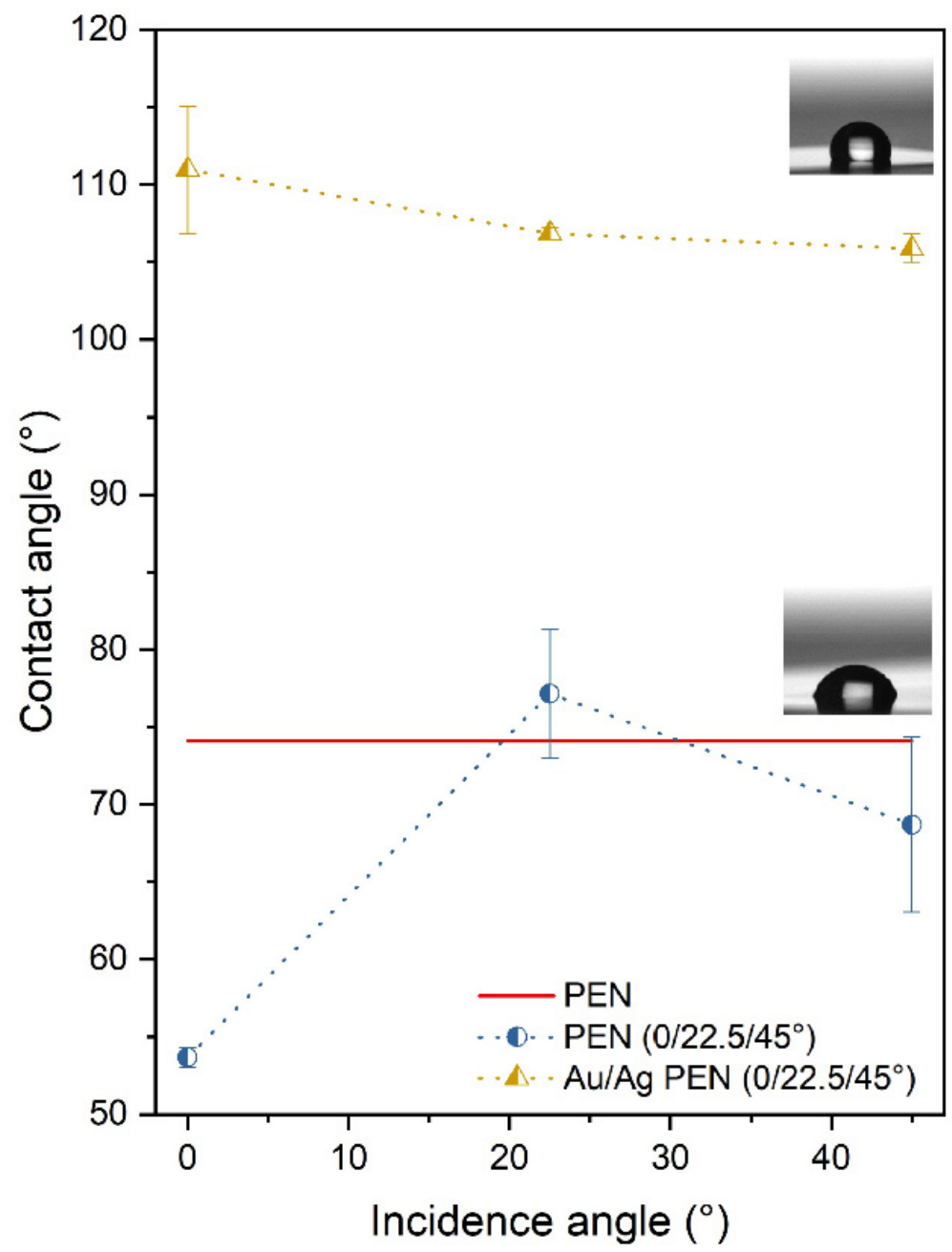

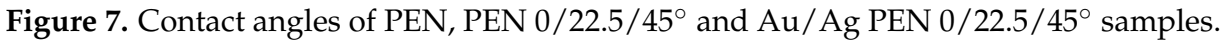

\subsection{Release of $\mathrm{Ag}^{+}$and $\mathrm{Au}^{n+}$}

Regarding the leachates of the PEN and the Au/Ag PEN 0/22.5/45 samples, concentrations of released $\mathrm{Ag}^{+}$and $\mathrm{Au}^{\mathrm{n}+}$ ions were determined using ICP-MS at the 3 and $24 \mathrm{~h}$ incubation times (Figure 8a). The physiological solution without samples and the leachate of the PEN were used as controls. The measured concentrations of metal ions increased with the increasing incidence angle of the laser beam, which probably relates to the increase of free space between the individual wires enabling better ion release in a water environment. Although the layer thicknesses of gold and silver were similar, the concentrations of $\mathrm{Ag}^{+}$were much higher compared to $\mathrm{Au}^{\mathrm{n}+}$. The explanation of this phenomenon is quite simple: (i) Gold is a much more noble metal compared to silver and (ii) due to characteristic metal distribution, gold was partially covered by silver on the tops of the ridges. 
(a)

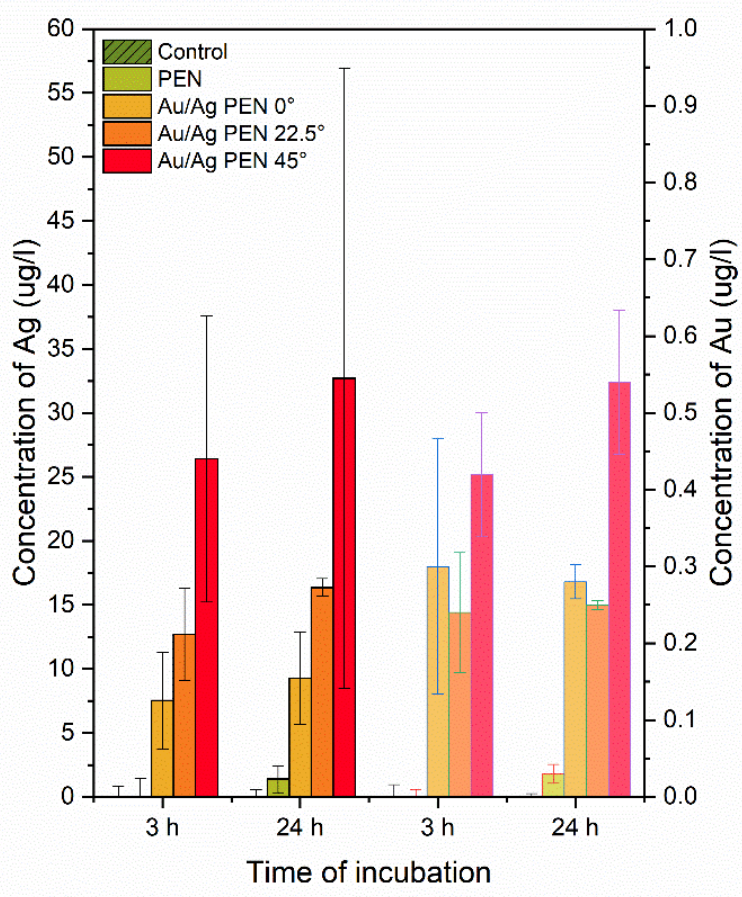

(b)

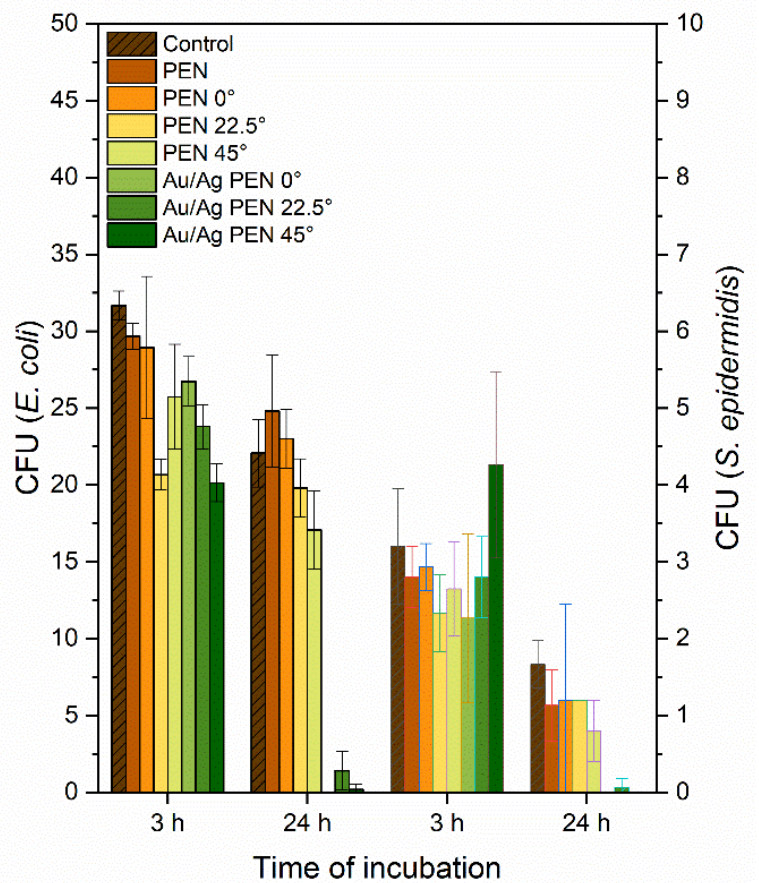

Figure 8. Concentrations of released $\mathrm{Au}^{\mathrm{n}+}$ and $\mathrm{Ag}^{+}$ions determined by ICP-MS (a) and data from antibacterial tests (E. coli,

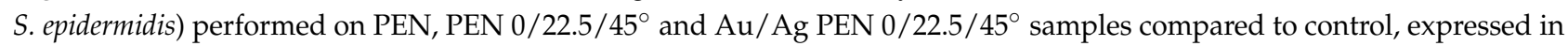
CFU values (b).

\subsection{Antibacterial Tests}

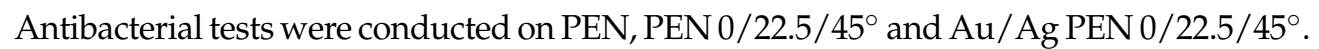
Gram-negative (Escherichia coli) and Gram-positive (Staphylococcus epidermidis) bacteria were used, as they are two of the most common pathogens that participate in biomaterial-related bacterial infections. The antibacterial activity of the prepared nanowires was affected primarily by the presence of silver, which was implied from the ICP-MS analysis (Figure 8a). At an incubation time of $3 \mathrm{~h}$ (see Figure $8 \mathrm{~b}$ ), no antibacterial effect was observed against either bacteria strain. In this case, the effect was quite insignificant for $E$. coli and fully absent for S. epidermidis. While the CFU values for PEN and PEN $0 / 22.5 / 45^{\circ}$ compared to control samples were similar, the values of the CFU for $\mathrm{Au} / \mathrm{Ag}$ PEN $0 / 22.5 / 45^{\circ}$ were slightly lower. Here a bacteria growth slowdown was observed, but not total inhibition. At the $24 \mathrm{~h}$ incubation time, pronounced inhibition of both bacteria was observed. The minimum inhibitory concentration (MIC) of silver ions for E. coli is $0.5-1 \mathrm{mg} \cdot \mathrm{L}^{-1}$ (dependent on the specific bacterial strain), the MIC of silver nanoparticles is $0.5-50 \mathrm{mg} \cdot \mathrm{L}^{-1}$ for $E$. coli and the $\mathrm{MIC}_{90}$ of silver nanoparticles is $6.25 \mathrm{mg} \cdot \mathrm{L}^{-1}$ for S. epidermidis (dependent on nanoparticle size) [41]. Thus, from the concentrations of released $\mathrm{Ag}^{+}$ions (ICP-MS) and MIC available from the literature [41], one can see that the antibacterial effect was largely caused by the surface morphology, the roughness, and the wettability. Moreover, the CFU values for $S$. epidermidis at the $24 \mathrm{~h}$ incubation time were significantly lower for control and modified samples compared to the CFUs at $3 \mathrm{~h}$. This phenomenon can be observed on samples of modified PEN with silver nanowires [16] and as a sputtered and annealed silver nanolayer on PI substrate [42]. S. epidermidis is usually more sensitive to this type of structure (with a high surface roughness) [43]. The cell walls of Gram-positive bacteria are also more permeable to positively charged particles (released metal ions) due to their composition, which is different from the cell walls of Gram-negative bacteria (E. coli). Therefore, the roughness considerably influenced the attachment of bacteria to the material surface. 


\subsection{Cytotoxicity}

A cytotoxic effect on human primary lung fibroblasts (Figure 9) was manifested at an incubation time of $24 \mathrm{~h}$ in the case of the modified samples and the modified samples with $\mathrm{Au} / \mathrm{AgNWs}$. The highest absorbance values were for control samples, which demonstrated that TCPS is an eligible material for the cultivation of eukaryotic cells [44]. The data also showed an increasing trend toward absorbance as incubation time increased for PEN 22.5 and $\mathrm{Au} / \mathrm{Ag}$ PEN 22.5 , while the absorbance values after longer incubation times (48 and $72 \mathrm{~h}$ ) were already comparable to the control and were almost two times higher than those at $24 \mathrm{~h}$. The explanation for this trend may be the initially difficult adaptation of the cell line to the modified rough surface, which is important for adhesion and subsequent proliferation [45]. The fundamental influence of the polymer surface itself on the cells is evident here, as the surfaces of the modified samples were not covered with metals, and the samples showed the same trends as the samples with deposited $\mathrm{Au} / \mathrm{Ag}$ nanowires. After longer incubation times ( 48 and $72 \mathrm{~h}$ ), the cells apparently adapted to the rough substrate, and the cytotoxic effects disappeared.

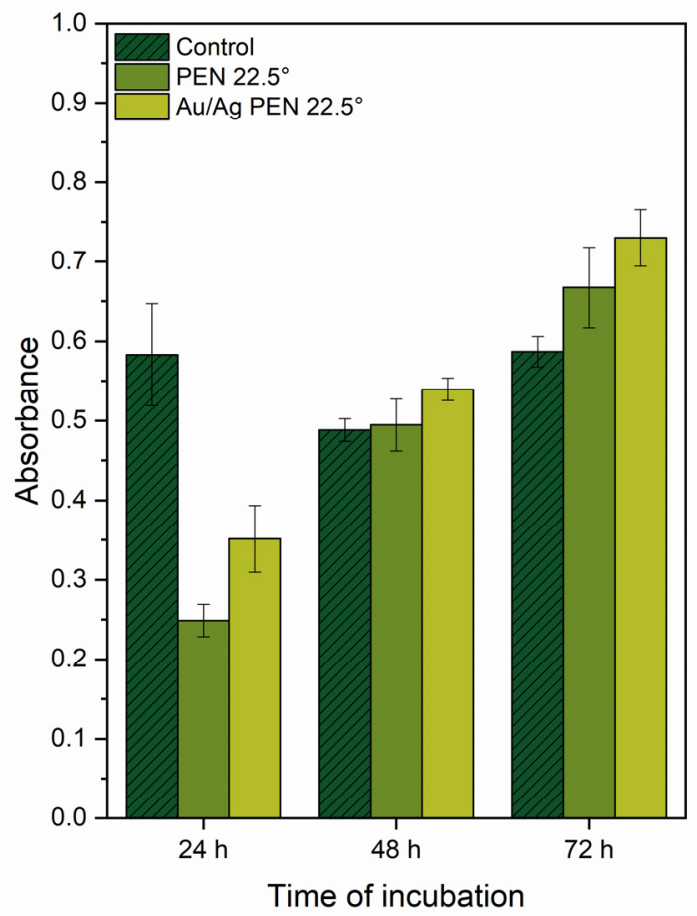

Figure 9. Decreasing cytotoxic effects of PEN 22.5 and $\mathrm{Au} / \mathrm{Ag}$ PEN $22.5^{\circ}$ samples, expressed by increasing absorbance.

Gold plays a key role in bimetallic nanowire behaviour during interactions with eukaryotic cells. Whereas gold cannot be considered an effective antibacterial agent, its presence is important in tissue interactions to provide biocompatibility with the final $\mathrm{Au} / \mathrm{AgNW}$ supported on the PEN. There are many studies about the toxicity of silver nanoobjects [28,46] including nanowires [27]. AgNWs produce antibacterial effects in the same bacteria strains as used in this work; unfortunately, they were found to be toxic in healthy human cells. However, the combination of silver and biocompatible metals appears to be a promising solution for decreasing the cytotoxic effects of silver. Gold deposited under the silver serves as a reducing agent because cells touch gold and silver simultaneously. In this case, the cells' low affinity was overcome, and even cell proliferation occurred after the long incubation, which was inspired by a study on GNP polymer fibre nanocomposites [47]. Thus, preparation of a Au/Ag nanocomposite on a modified polymer surface is supposed to create an antibacterial material with a considerably low cytotoxic effect. 


\section{Conclusions}

We have presented a straightforward and effective method for the preparation of bimetallic nanowires on laser-rippled PEN using a physical vapour deposition technique. The combination of laser treatment and vacuum evaporation is able to produce $\mathrm{Au} / \mathrm{AgNWs}$ that are homogeneously distributed over the ripples of the modified PEN surface. AFM and SEM images confirmed the periodic nanostructures, with the surface roughness of the deposited nanowires increasing as the incidence angle increased. EDS and AR-XPS spectroscopies revealed the lamination of silver and gold on the ripple tops; the concentration of silver was significantly higher than that of gold, and it had a considerable effect on the resulting antibacterial and cytotoxic properties of the materials. Generally, the Au/AgNWs inhibited the growth of $\mathrm{G}^{+}$and $\mathrm{G}^{-}$bacteria and were non-toxic to healthy eukaryotic cells. Thus, the combination of these metals enabled us to develop a very promising biocompatible material with antibacterial properties that makes it highly suitable for use in medical and pharmaceutical applications.

Author Contributions: Conceptualisation, writing—original draft preparation, visualisation, J.P.; sample preparation, M.K. and B.V.; ICP-MS analysis, T.H.; AFM analysis, funding acquisition, P.S.; data curation, V.Š.; methodology, supervision, writing - review and editing, J.S. All authors have read and agreed to the published version of the manuscript.

Funding: This research was funded by the Czech Science Foundation, grant number 21-05506S.

Data Availability Statement: The data presented in this study are available on request from the corresponding author.

Conflicts of Interest: The authors declare no conflict of interest.

\section{References}

1. Pryjmaková, J.; Kaimlová, M.; Hubáček, T.; Švorčík, V.; Siegel, J. Nanostructured Materials for Artificial Tissue Replacements. Int. J. Mol. Sci. 2020, 21, 2521. [CrossRef]

2. Slepička, P.; Siegel, J.; Lyutakov, O.; Kasálková, N.S.; Kolská, Z.; Bačáková, L.; Švorčík, V. Polymer nanostructures for bioapplications induced by laser treatment. Biotechnol. Adv. 2018, 36, 839-855. [CrossRef] [PubMed]

3. Aderson, J.M. Inflammatory Response to Implants. ASAIO J. 1988, 34, 101-107. [CrossRef] [PubMed]

4. Nicolle, L.E. Catheter associated urinary tract infections. Antimicrob. Resist. Infect. Control 2014, 3, 23. [CrossRef]

5. Pavithra, D.; Doble, M. Biofilm formation, bacterial adhesion and host response on polymeric implants-Issues and prevention. Biomed. Mater. 2008, 3, 034003. [CrossRef]

6. Fisher, L.E.; Hook, A.L.; Ashraf, W.; Yousef, A.; Barrett, D.A.; Scurr, D.J; Chen, X.; Smith, E.F.; Fay, M.; Parmenter, C.D.; et al. Biomaterial modification of urinary catheters with antimicrobials to give long-term broadspectrum antibiofilm activity. J. Control. Release 2015, 202, 57-64. [CrossRef] [PubMed]

7. Chellamani, K.P.; Balaji, R.S.; Sudharsan, J. Antibacterial properties of allopathic drug loaded polycaprolactone nanomembrane. J. Acad. Ind. Res. 2013, 2, 341-344.

8. Muszanska, A.K.; Rochford, E.T.J.; Gruszka, A.; Bastian, A.A.; Busscher, H.J.; Norde, W.; Van Der Mei, H.C.; Herrmann, A. Antiadhesive Polymer Brush Coating Functionalized with Antimicrobial and RGD Peptides to Reduce Biofilm Formation and Enhance Tissue Integration. Biomacromolecules 2014, 15, 2019-2026. [CrossRef]

9. Roe, D.; Karandikar, B.; Bonn-Savage, N.; Gibbins, B.; Roullet, J.-B. Antimicrobial surface functionalization of plastic catheters by silver nanoparticles. J. Antimicrob. Chemother. 2008, 61, 869-876. [CrossRef]

10. Siegel, J.; Kaimlová, M.; Vyhnálková, B.; Trelin, A.; Lyutakov, O.; Slepička, P.; Švorčík, V.; Veselý, M.; Vokatá, B.; Malinský, P.; et al. Optomechanical Processing of Silver Colloids: New Generation of Nanoparticle-Polymer Composites with Bactericidal Effect. Int. J. Mol. Sci. 2020, 22, 312. [CrossRef]

11. Riveiro, A.; Maçon, A.L.B.; Del Val, J.; Comesaña, R.; Pou, J. Laser Surface Texturing of Polymers for Biomedical Applications. Front. Phys. 2018, 6, 16. [CrossRef]

12. Allen, N.S. A study of the light absorption properties of polymer films using UV-visible derivative spectroscopy. Polym. Photochem. 1981, 1, 43-55. [CrossRef]

13. Michaljaničová, I.; Slepička, P.; Rimpelova, S.; Kasálková, N.S.; Švorčík, V. Regular pattern formation on surface of aromatic polymers and its cytocompatibility. Appl. Surf. Sci. 2016, 370, 131-141. [CrossRef]

14. Barb, R.-A.; Hrelescu, C.; Dong, L.; Heitz, J.; Siegel, J.; Slepička, P.; Vosmanská, V.; Svorcik, V.; Magnus, B.; Marksteiner, R.; et al. Laser-induced periodic surface structures on polymers for formation of gold nanowires and activation of human cells. Appl. Phys. A 2014, 117, 295-300. [CrossRef] 
15. Siegel, J.; Slepička, P.; Heitz, J.; Kolská, Z.; Sajdl, P.; Švorčík, V. Gold nano-wires and nano-layers at laser-induced nano-ripples on PET. Appl. Surf. Sci. 2010, 256, 2205-2209. [CrossRef]

16. Kaimlová, M.; Nemogová, I.; Kolarova, K.; Slepička, P.; Švorčík, V.; Siegel, J. Optimization of silver nanowire formation on laser processed PEN: Surface properties and antibacterial effects. Appl. Surf. Sci. 2019, 473, 516-526. [CrossRef]

17. Suarasan, S.; Focsan, M.; Soritau, O.; Maniu, D.; Astilean, S. One-pot, green synthesis of gold nanoparticles by gelatin and investigation of their biological effects on Osteoblast cells. Colloids Surf. B Biointerfaces 2015, 132, 122-131. [CrossRef] [PubMed]

18. Ko, W.-K.; Heo, D.N.; Moon, H.-J.; Lee, S.J.; Bae, M.S.; Lee, J.B.; Sun, I.-C.; Jeon, H.B.; Park, H.K.; Kwon, I.K. The effect of gold nanoparticle size on osteogenic differentiation of adipose-derived stem cells. J. Colloid Interface Sci. 2015, 438, 68-76. [CrossRef]

19. Peterbauer, T.; Yakunin, S.; Siegel, J.; Hering, S.; Fahrner, M.; Romanin, C.; Heitz, J. Dynamics of Spreading and Alignment of Cells Cultured In Vitro on a Grooved Polymer Surface. J. Nanomater. 2011, 2011, 413079. [CrossRef]

20. Crabtree, J.H.; Burchette, R.J.; ASiddiqi, R.; Huen, I.T.; Hadnott, L.L.; Fishman, A. The efficacy of silver-ion implanted catheters in reducing peritoneal dialysis-related infections. Perit. Dial. Int. 2003, 23, 368-374.

21. Guo, L.; Yuan, W.; Lu, Z.; Li, C. Polymer/nanosilver composite coatings for antibacterial applications. Colloids Surf. A Physicochem. Eng. Asp. 2013, 439, 69-83. [CrossRef]

22. Mahmoodi, S.; Elmi, A.; Nezhadi, S.H. Copper Nanoparticles as Antibacterial Agents. J. Mol. Pharm. Org. Process. Res. 2018, 6, 1-7. [CrossRef]

23. Panacek, A.; Kvitek, L.; Prucek, R.; Kolar, M.; Vecerova, R.; Pizurova, N.; Sharma, V.K.; Nevecna, T.; Zboril, R. Silver colloid nanoparticles: Synthesis, characterization, and their antibacterial activity. J. Phys. Chem. B 2006, 110, 16248-16253. [CrossRef]

24. Zhang, Y.; Dasari, T.P.S.; Deng, H.; Yu, H. Antimicrobial Activity of Gold Nanoparticles and Ionic Gold. J. Environ. Sci. Heath Part C 2015, 33, 286-327. [CrossRef] [PubMed]

25. Braydich-Stolle, L.; Hussain, S.; Schlager, J.J.; Hofmann, M.-C. In Vitro Cytotoxicity of Nanoparticles in Mammalian Germline Stem Cells. Toxicol. Sci. 2005, 88, 412-419. [CrossRef] [PubMed]

26. Asharani, P.V.; Mun, G.L.K.; Hande, M.P.; Valiyaveettil, S. Cytotoxicity and Genotoxicity of Silver Nanoparticles in Human Cells. ACS Nano 2009, 3, 279-290. [CrossRef]

27. Polívková, M.; Štrublová, V.; Hubáček, T.; Rimpelová, S.; Švorčík, V.; Siegel, J. Surface characterization and antibacterial response of silver nanowire arrays supported on laser-treated polyethylene naphthalate. Mater. Sci. Eng. C 2017, 72, 512-518. [CrossRef] [PubMed]

28. Ton-That, C.; Shard, A.; Bradley, R.H. Thickness of Spin-Cast Polymer Thin Films Determined by Angle-Resolved XPS and AFM Tip-Scratch Methods. Langmuir 2000, 16, 2281-2284. [CrossRef]

29. Herigstad, B.; Hamilton, M.; Heersink, J. How to optimize the drop plate method for enumerating bacteria. J. Microbiol. Methods 2001, 44, 121-129. [CrossRef]

30. Novotna, Z.; Reznickova, A.; Rimpelova, S.; Vesely, M.; Kolska, Z.; Svorcik, V. Tailoring of PEEK bioactivity for improved cell interaction: Plasma treatment in action. RSC Adv. 2015, 5, 41428-41436. [CrossRef]

31. Slepička, P.; Nedela, O.; Siegel, J.; Krajcar, R.; Kolska, Z.; Svorcik, V. Ripple polystyrene nano-pattern induced by KrF laser. Express Polym. Lett. 2014, 8, 459-466. [CrossRef]

32. Slepička, P.; Chaloupka, A.; Sajdl, P.; Heitz, J.; Hnatowicz, V.; Švorčík, V. Angle dependent laser nanopatterning of poly (ethylene terephthalate) surfaces. Appl. Surf. Sci. 2011, 257, 6021-6025. [CrossRef]

33. Bäuerle, D. Laser Processing and Chemistry, 3rd ed.; Springer-Verlag: Berlin/Heidelberg, Germany; New York, NY, USA, 2000.

34. Csete, M.; Bor, Z. Laser-induced periodic surface structure formation on polyethylene-terephthalate. Appl. Surf. Sci. 1998, 133, 5-16. [CrossRef]

35. Belardini, A.; Larciprete, M.C.; Centini, M.; Fazio, E.; Sibilia, C.; Bertolotti, M.; Toma, A.; Chiappe, D.; De Mongeot, F.B. Tailored second harmonic generation from self-organized metal nano-wires arrays. Opt. Express 2009, 17, 3603-3609. [CrossRef]

36. Tyler, B.J.; Castner, D.G.; Ratner, B.D. Regularization: A stable and accurate method for generating depth profiles from angledependent XPS data. Surf. Interface Anal. 1989, 14, 443-450. [CrossRef]

37. Vollath, D. Optical properties. In Nanoparticles-Nanocomposites-Nanomaterials: An Introduction for Beginners; WILEY-VCH Verlag GmbH \& Co. KGaA: Weinheim, Germany, 2013; pp. 181-228.

38. Gunawidjaja, R.; Kharlampieva, E.; Choi, I.; Tsukruk, V.V. Bimetallic Nanostructures as Active Raman Markers: Gold-Nanoparticle Assembly on 1D and 2D Silver Nanostructure Surfaces. Small 2009, 5, 2460-2466. [CrossRef]

39. Joo, H.-Y.; Kim, H.J.; Kim, S.J.; Kim, S.Y. Spectrophotometric analysis of aluminum nitride thin films. J. Vac. Sci. Technol. A 1999, 17, 862-870. [CrossRef]

40. Murakami, D.; Jinnai, H.; Takahara, A. Wetting Transition from the Cassie-Baxter State to the Wenzel State on Textured Polymer Surfaces. Langmuir 2014, 30, 2061-2067. [CrossRef]

41. Chernousova, S.; Epple, M. Silver as Antibacterial Agent: Ion, Nanoparticle, and Metal. Angew. Chem. Int. Ed. 2013, 52, 1636-1653. [CrossRef]

42. Siegel, J.; Polívková, M.; Staszek, M.; Kolarova, K.; Rimpelova, S.; Švorčík, V. Nanostructured silver coatings on polyimide and their antibacterial response. Mater. Lett. 2015, 145, 87-90. [CrossRef]

43. Chen, M.; Yu, Q.; Sun, H. Novel Strategies for the Prevention and Treatment of Biofilm Related Infections. Int. J. Mol. Sci. 2013, 14, 18488-18501. [CrossRef] 
44. PeŠŠková, V.; Kubies, D.; Hulejová, H.; Himmlová, L. The influence of implant surface properties on cell adhesion and proliferation. J. Mater. Sci. Mater. Med. 2007, 18, 465-473. [CrossRef] [PubMed]

45. Ross, A.M.; Jiang, Z.; Bastmeyer, M.; Lahann, J. Physical Aspects of Cell Culture Substrates: Topography, Roughness, and Elasticity. Small 2012, 8, 336-355. [CrossRef] [PubMed]

46. Marambio-Jones, C.; Hoek, E.M.V. A review of the antibacterial effects of silver nanomaterials and potential implications for human health and the environment. J. Nanoparticle Res. 2010, 12, 1531-1551. [CrossRef]

47. Jung, D.; Minami, I.; Patel, S.; Lee, J.; Jiang, B.; Yuan, Q.; Li, L.; Kobayashi, S.; Chen, Y.; Lee, K.-B.; et al. Incorporation of functionalized gold nanoparticles into nanofibers for enhanced attachment and differentiation of mammalian cells. J. Nanobiotechnol. 2012, 10, 1-10. [CrossRef] [PubMed] 